\title{
Entering The Tourism Industry And Generation Y "Prospects": Turkish Entrepreneurs Planning To Enter The American Market
}

Bahaudin Mujtaba, (Email: Mujtaba@nova.edu), Nova Southeastern University Shahan Karadayi, (Email: karadayi@nova.edu), Nova Southeastern University

\begin{abstract}
Many foreign firms competing globally are trying to secure a piece of the tourism market share in the United States. However, people are finding that starting and expanding a new business in the tourism industry to American consumers in the United States can be challenging. This document explores the strategy and mission of Turkish entrepreneurs assessing the tourism industry from a global perspective and choosing the United States to start securing a piece of the market with Generation $Y$ individuals due to the country's economic factors, the spending power of the average person, the hunger for cultural awareness and diversity, and the political stability of the country. Overall, the marketing strategy of the organization is discussed for the following factors: the product/service, pricing, distribution, and promotion. For calculating the budget, two options which are the fixed costs and the variable costs options are discussed.
\end{abstract}

The focus of this study was to set up a business in a country such as the United States because such a country would have various types of diverse markets. The average income of most consumers in the developing countries seems to be sufficient to purchase services for pleasure, cultural awareness and other desires they would like to pursue. As such, it makes good business sense to enter this competitive market by differentiating one's offering through price, product and service quality to guarantee initial success.

\section{Market Positioning and Environmental Analysis}

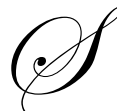

tarting and expanding a new business in the tourism industry to American consumers in the United States requires strategic vision, market research, planning, and effective marketing. Marketing involves analyzing customer needs and securing information needed to produce goods and services in a timely manner. Consumers' buying patterns and behaviors differ among different market segments within a nation or geographical population. Before entering any market, the following questions should be asked: Is there a demand for such a product/service? How competitive is the market for this product/service? How do cultural factors impact a business that is owned by a Turkish parent firm? How is the political situation and advances in technology?

In this case, the Turkish entrepreneurs are looking into entering the American tourism industry through a newly formed organization named "RebSen Travel Agency" because of their unique cultural background with the young generation and their philosophy of treating customers like guests to deliver superior value for their clients.

The entrepreneurs were raised and brought up in Turkey which is a Middle Eastern country with a population of 70 million people. About $90 \%$ of the total population is moderately religious, mostly struggling to become an economically stable society. It has been a secular country since 1923, in which the founder of the Turkish republic called Ataturk established the democratic and secular Turkey. About half of the population (35 million) is 
in the range of 20-40 years of age. As such, Turkey may be one of the largest countries that has a high percentage of young population in the Middle East, maybe in Europe as well. Nevertheless, the government has not come up with a feasible long-term strategy to benefit from the wisdom, energy and enthusiasm of this generation. In comparison to Western countries, despite the fact that the percentage of young generation is higher in Turkey, the average age of employees in corporations tends to range close to 40's. In other words, employees are generally older in Turkey than that of other countries in Europe, and the young generation suffers from not being able to find enough opportunities to start their professional business life. So, these Turkish entrepreneurs, having had plenty of experience with the young generation, are focused on creating an organization that caters to the preference of Generation Y group.

The main mission of this new organization is to focus on the customers' needs and to complete and complement this market's missing desires. The organizational philosophy is to be different than others in the industry while understanding that different is not necessarily better but better is always different. The objective of this organization is to locate a tourism market where one can compete effectively and successfully initially while having a minimum of a $20 \%$ growth rate on an annual basis in the prospective years. To look at the market demand we had to look at the following points: target audience, geographic segmentation, demographic segmentation, and benefit-based segmentation. The marketing strategy is defined for the following factors: the product/service, pricing, distribution, and promotion. For calculating the budget, two options which are the fixed costs and the variable costs options are explored.

\section{Understanding the Market}

Marketing involves analyzing customers' needs, securing information needed to design and produce goods and services according to the customers' expectations, as well as creating and maintaining a healthy relationship with customers and suppliers in the long-term. Buyer behavior differs among nations and often among market segments within each country and various cultures and sub-cultures. Marketers must carefully match their marketing strategies to local customs, tastes and living conditions.

The market for this study is tourism industry in the United States of America, more specifically the west coast cities. The target population is the young generation, due to this specific population we are going to more specifically start by focusing on university students. According to the marketing research on this market, it is determined that there is a high potential for usage of this service in the young generation which includes both American residential students and international students living in the USA. That is why this new organization believes that the United States has already had various types of markets and can still accommodate more due to consumer preferences and desire for products and services that are different. That's why this organization decided to get into the U.S market first instead of applying to several different markets. The first consideration of this operation was to see the cost of the marketing plan at this initial market. The second main consideration was to see if the wages and income of the market customers is sufficient to purchase this type of service in the tourism industry. In addition to this, the strength of American economy in parallel with that GPC (gross per capita) led to the decision to develop and implement our marketing strategy in U.S.

Seasonally, based on initial research, the objective is to serve this package to 2,160 people each year. This given amount of people is counted in terms of the above data over each season. Season is defined as starting from May 23, 2004 and is ending September 5, 2004. Furthermore, customers will be placed into groups and each group will have 135 people. Three buses will be reserved to accommodate the transportation needs of each group. There will be 16 back-to-back groups identified as Green-group and Blue-group to make up the total number of each season $(16 \times 135=2160)$ for 2004 . The 2005 seasonal market target is going to be 2592 customers because of the $20 \%$ annual growth objective $(2160+(2160 \times 20 \%)=2592)$.

\section{Environment Considerations in the Tourism Industry}

Environmental scanning is a critical part of market research. The best way to make an effective strategic plan for the market is to find out how environmental factors such as economic, political-legal, competitive, social- 
cultural or technological impact the targeted market. Before entering a foreign market, the following elements and questions need to be considered:

1. Demand. Do foreign consumers need the company's goods and services? Will the demand rise or fall in the coming five years?

2. Competitive environment. How do supplies currently reach the market? How will supplies be secured in the future?

3. Economic environment. Are people able to buy such services in the current environment? How do cultural factors affect business opportunities?

4. Political-legal environment. What are the local laws? Do any legal restrictions complicate entering the market?

5. Technological environment. To what degree are technological innovations used by organizations, suppliers and consumers in the market?

Since the organization is in the tourism industry, social-cultural, competitive and technological effects have the most priority over the other environmental effects. There is no doubt that one of the important elements of being successful in the tourism industry is introducing and serving various cultural aspects to people from different perspectives. So the cultural norms, practices and paradigms of each location should be precisely described and detailed. If the culture of the market that you choose is not common or familiar with the culture of the consumers you serve then you should immediately resort to other strategies for the market plan. Furthermore, as mentioned in SWOT (Strengths, Weakness, Opportunities and Threats) analysis a company's strengths reflect its core competencies, which are capabilities that customers value and competitors find difficult to duplicate. The things that create a competitive position in the market can be given as follows:

1. The uniqueness of the service/product itself.

2. The price should be considered in terms of the total value and the target audience.

3. Effectively responding to customers' questions and challenges quickly.

4. Keeping one's finger on the pulse of the customer by regularly surveying and asking what customers want and need.

5. Create a unique service that is consistently providing more value to consumers than others in the industry.

In the case of providing service, one must provide quality service consistently to all customers in every aspect of the business before, during and after each transaction. We know the fact that customers look for a better service and more value while they would prefer to pay less by searching around in today's competitive market. In addition to this, competition occurs when more than one company serves the same market with similar products/services or the same products/services. According to our marketing plan, our aim is to provide high quality service with minimum prices. That's why when we are preparing our marketing plan we try to create a package, which should be suitable for a great percentage of targeted audience. Furthermore, we believe that we offer the best prices due to efficient use of human resources and low cost. Also, we ensure that we get the least prices from the suppliers, vendors and other companies we partner with to serve the customers.

On the other hand, there are some environmental factors which we have no control over that must be considered as well. Such factors involve a country's growth, inflation, government regulations, and other variables that impact the market. The positive changes of the country such as growth can bring about many advantages for the market. In fact, positive country growth directly affects the buying power. Moreover, this positive growth effects the motivation of the society. Inflation is one of the components of economical growth either positive or negative depending on how long it lasts. Currency is an important factor in determining the people's expenses when they travel from one country to another country. Government regulations effect the purchasing decision making of consumers. Also, in the tourism industry, a country's relationship with others plays a key role. In the market plan, the reason that this organization chose the U.S. market is because of the good relationship which exists between the United States and Turkey. 


\section{Competition in the Tourism Industry}

As organizations vie with one another to satisfy customers, the interactive exchange creates the competitive environment. Marketing decisions by each individual firm influence consumer responses in the marketplace. As a consequence, decision makers must continually monitor competitors' marketing activities, their products, channels, prices, and promotional efforts. Often times, marketers can face at least three types of competition.

1) The most direct form of competition occurs among marketers of similar products.

2) Another form of competition involves products that can be substituted for one another.

3) Yet another form of competition occurs among all organizations that compete for consumer's purchases.

In developing a competitive strategy, an organization should answer the following questions:

1) Will competition bring about more growth for the organization in the short term and in the long-term?

2) Is competition a value adder or a value destroyer for this organization?

3) Should we compete?

4) If so, in what markets should we compete?

5) How should we compete and with which organizations?

The answer of many of these questions depends on the firm's resources, objectives, and expected profit potential. The answers also require marketers to acknowledge their firm's limited resources (sales personnel, advertising budgets, product development capability and others alike). Overall, they require marketers to make product, pricing, distribution, and promotional decisions that give the firm a competitive advantage in the marketplace.

The high potential for growth and profit in the U.S. market is very attractive to all foreign tourism companies. That's why there is so much competition in the marketplace. There is a great potential in the young generation who desires to have experiences with different cultures and histories. The major international competitors are especially the Greek and Egyptian travel agencies. That is to say, there seems to be stiff competition between these companies because of the historical values and the similar natural beauties that cover centuries of history. Then, there are national competitors within Turkey that have a good reputation in the market, such as Pamfilya travel agency and Aldo travel agency. For competing with international competitors, the strategy is to parallel the existing methods in pricing the package, quality services and the overall product package decision. First, there is the need to compare the price and service given by other travel agencies in the market and then one should search the content and details of packages offered by competitors. Since the high quality service with desired product package and low price are attractive to the buyers, the main objective is to serve this kind of package at the initial stage in order to have a successful entry into the market. On the other hand, in competition with national competitors we mainly focus on two things; which are the prices we assign for our package, and the services we provide for customer requirements. In this case, the strategy is to give the lowest price while providing a high quality service.

\section{Marketing Goals \& Differentiation}

An organization lays out its basic objectives, or goals in its mission. A mission statement provides the essential purpose for the existence of the organization that differentiates the company from others. A mission provides guidance and objectives for the organization's resources to be strategically used to enhance stakeholder value. These objectives in turn guide development of supporting marketing objectives and plans. Objectives should state specific intentions for the various stakeholders and what they value. For example, increase in profits and attainment in share of the market, or increase on sales are some aspects of specific objectives that drive human behavior and an organization's strategies.

The current mission and purpose is to focus on the customers' needs and to complete the market's missing parts. The following objectives support the underlying aim of this mission. 
- $\quad$ First of all, we try to differentiate ourselves from competitors in the market by using various strategies such as providing low rate package prices with proven high quality service while responding to the customers' needs and demands in a quick manner.

- $\quad$ Second, we provide a flexible and comfortable atmosphere for customers. This is an environment where customers choose to go repeatedly.

- $\quad$ Furthermore, we try to take care of our customers by providing unique historical and cultural facts in ways that they love and appreciate.

- We keep our fingers on the pulse of the customer by listening to them and getting their feedback so we can better serve them with new products and services as well as to continuously enhance the total value of the package for them.

- In addition to this, we are planning to have a minimum of a $20 \%$ market growth, and a profit margin that is better than the industry average.

Since this is a new company in the tourism market place, we know that we are going to be faced with some disadvantages at the initial stages. These disadvantages can be categorized under several basic areas. The first disadvantage is that customer trust can be low because we are new and inexperienced in this market place. The second disadvantage is that the cost of establishing a new business in the U.S. is high which prevents some new entries of entrepreneurs that cannot raise the funds.

On the other hand, we have some advantages which carry our organization to the top positions after competing against the other competitors in tourism industry. One of the advantages we have is that we transfer all the accumulated experience to deliver superior value to customers by treating them as guests and training people to offer the best total value to all guests consistently. Such philosophy and its successful implementation help the organization produce useful and quality service and respond to customer demands in a fast and efficient manner. The second advantage is that we first find out the missing parts and services in the market and then by providing this service better than others, we create opportunities demanded by customers. Another advantage is that the companies we partner/cooperate with are the well known, highly trusted and have great market share in their industry. For instance, these companies are Turkish Airlines, Ulusoy ground transportation, Continental Hotel, and others. Finally, the important advantage is that we have efficient capital to reach our goals and missions.

\section{Market Segmentation and Evaluating Market Demand}

The divisions of the total market into smaller, relatively homogeneous groups are called market segmentation. Effective segmentation depends on the following basic requirements:

1) The market segment must present measurable purchasing power and size.

2) Marketers must find a way to effectively promote and serve the market segment.

3) Marketers must identify segments that are sufficiently large enough to give them good profit potential.

4) The firm must target segments that match its marketing capabilities. Targeting a large number of niche markets can produce an expensive, complex, and inefficient strategy.

Geographic segmentation provides a way to examine the population characteristics. While population numbers indicate the overall size of market, other geographic indicators, such as job growth, can also give useful guidance to marketers, depending on the type of products they sell. Geographic areas also vary in populationmigration patterns. As people migrate from one geographic area to another, regional consumers' requirements always change.

In demographic segmentation, consumer groups are defined according to demographic variables such as gender, age, income, occupation, education, household size, and stage in the family life cycle. Gender is an obvious variable that helps to define the markets for certain products. When segmenting by gender, marketers need to be sure they are targeting consumers correctly in order to effectively capitalize on their resources. Many companies develop some products specifically to meet the needs of people in a certain age category. There are basically two generation groups: Generation X and Generation Y. Generation X category of individuals were born between 1965 
and the late 1970s. Specific features of Generation X are delaying marriage and careers, accept cultural diversity, and value the quality of personal life above work life. On the other hand, people in Generation Y category were born in between 1977 and 1994. This generation is highly computer-literate, looking to the Internet for much of their entertainment and information about goods and services.

\section{Understanding Generation Y Characteristics}

In the Generation Y (Gen Y) segment of the American market, consumers have needs and preferences that are very different than any other generation due to their upbringing and socialization factors. Organizations must pay attention to Gen Y-ers as they make up about 70 million Americans born during the 1977 through 1994. Their shared experiences have included invasion of Iraq, the removal of Taliban in Afghanistan, the attacks on New York's Twin Towers during September 11 of 2001, the widespread popularity of individuals associated with terrorism, the impeachment trails of President Clinton over sex allegation statements, the Columbine high school shootings, several cult members of different groups committing suicide, the fuss over the Y2K challenges which did not cause the expected problems, the wave of electronic shopping/banking, and the Dot.Com bust among many others. They also seem to prefer video games, internet and DVD compared to mass media television and movies.

Generation $\mathrm{Y}$ individuals are more technologically savvy and more interactive than any other generation prior to them. It is estimated that those who are between the ages of 18-24 years of age tend to spend about ten hours online each week while watching television about ten hours as well. They tend to heavily engage in video games and instant messaging through their computers while listening to the latest and diverse music online. Researchers conclude that organizations can best reach this group via word-of-mouth advertisement which can reach millions of individual instantly through the connectivity of technology savvy individuals. Gen Y-ers tend not to take too much risk as they have seen the Dot.Com bust and the downfall of large organizations such Enron and WorldCom where people either invested heavily in them for quick returns or their leaders lied to their stakeholders. They also distrust media because they know politicians and governments tend to use media to sway perceptions. They feel as though they are living in a very uncertain world where much animosity exists between individuals in different countries due to their personal beliefs which may be very different than that of Americans. A good percentage of the Gen Y-ers are worried about crimes, wars, and terrorism attacks. Research has shown that while concerns about possible terrorist attacks on the United States either were reduced or stayed the same for many individuals, Gen Y individuals' level of concern about such attacks actually increased from $51 \%$ in 2002 to $61 \%$ in the year 2003. This two digits or eleven percentage increase in the level of concern could be due to the widespread mistrust of the American government, by outsiders, which is seen as an imperialist trying to exercise aspects of colonialism with developing countries.

Generation Y individuals tend to be open to diversity of ideas, cultures, music, and points of views. They are able to adapt quickly to new lifestyles and cultures compared to their parents. They are not hard core "my way or the highway" or dichotomous individuals as they believe in contrasting points of views. Their values include diversity, dignity, fairness, and equality for people in all respects. They also like to challenge the status quo and extreme paradigms as they want proof in order to believe and trust others (they may say "Show me the money" as in the movie Jerry Maguire with Mr. Tom Cruise as the lead actor). They do not like telemarketers nor do they like those who are involved in hard sell. This generation is best reached by friends, colleagues and technology that is fun, exciting and in touch with their values. They seem to like reality shows because they seem to be more natural than the regular television shows.

Generation $\mathrm{Y}$ employees tend to be very interactive and they value learning, flexibility and mutual trust. They follow the rules of their organizations and professions and they tend to be good team players with challenging assignments. They are confident, time-impoverished, can multi-task better than previous generations, and are willing to work hard for good causes. They are also willing to leave organizations for others that are more fair and loyal to their people. The same is true for their choices in buying products, services and vacations.

This generation has been called the "digital natives" who are connected at all times through their laptops and state of the art wired telephones. They seem to be immersed in a "fun focused" world and heavily involved with 
fun technology. They value entertainment, humor, fun, excitement and unique cultural experiences which seem to drive their buying patterns and behaviors. Values theory states that what people value drives their behaviors and this is certainly the case with individuals of this generation. They don't watch regular television shows or big Hollywood movies which attracted previous generations in this age group because their values are different. As such, they are considered to be immune to the traditional marketing and advertising strategies which organizations have used in their conquest for more revenues. Generation Y-ers tend to trust real time information coming from their friends, family members, colleagues, and those in the online community that tend to speak honestly from their hearts about movies, television shows, and best products. They value reality which is why many of them are watching the "reality shows" on television. They are the "just-in-time" (JIT) generation of individuals and get information on a JIT basis for product buying choices. They want information that is of use to them in their current situation and lives which is why they rely so much on instant information available on the internet for instant customization. So, "word of mouth" advertisement seems to be the best strategy with Generation Y group of individuals.

\section{Benefit based Segmentation}

This approach focuses on the attributes that people seek in a good or service and the benefits they expect to receive from such goods or services. It groups consumers into the segments based on what they want a product to do for them. We at RebSen Travel Agency, target the young generation group between 18 and 30 years old which are mainly Generation Y individuals and those who were born in the later years of Generation X category. In our program we respond to fulfill the needs and the demands of this age group. That is to say, in our package we mainly involve three basic components, enjoyed by this population, which are entertainment, historical and natural places for visitation, and introducing different culture. The reason that we choose this age group is because their generation requires various types of demands and needs that we can fulfill successfully. We choose U.S market as a location because there is a high purchasing power and great number of young generation from different cultures or they would like to be exposed to different cultures. This richness of social and cultural potential allows us to easily reach many different cultures located in same market. Research on the average income of the targeted customers, which are mainly students and those who are at their initial stages of employment, implied differences in the following area:

- $\quad$ Their expenses are paid for or supported by parents.

- $\quad$ They could be participating in business activities while enjoying our services.

- $\quad$ Some customers pay fully for themselves because they are currently employed or they are earning money from part time jobs for summer vacation.

Basically, the target is a person who can afford to pay $\$ 1399$ for a full package. Perhaps, the more specific target is to sell this package to middle class population. In this segment of the business the gender and lifestyle are not critical factors since everyone wants similar experiences based on their age and technology savvy backgrounds. The most important factor in the industry is providing quality service in transportation, hotels, restaurants, and experienced tour guides. In addition to these, personal communication between company and customers is important because customers should feel comfortable during the vacation. That's why our mission is to give maximum attention to our customers. When one aspect of the value-added chain mentioned above is missing, then the business is going to lose both current and potential customers. According to marketing research on the west coast of U.S., it is concluded that at least 5 million individuals can purchase our product. It does not mean that all the people we determined are going to buy our product but they are the target market. The first goal, for the first year, is to reach the targeted number which is 2160 people in 2004. Based on the overall population numbers, we can say that it indicates a good size market for this product. Also there seems to be a consistent growth rate in these cities but there is a fluctuating pattern of immigration from foreign countries as well. Since the U.S. population is directly effected from the immigration of other countries, the population seems to have more of a need for culturally diverse experiences that are different from their local norms. That is why we are planning at least a $20 \%$ increase in the number of customers for the coming years. 


\section{Marketing Mix Considerations and Strategies}

Just as manufacturers struggle to find the best product mixes, service firms must also identify the service mixes that will successfully attract and satisfy consumers. The target market picked for a service influences the elements of the service mix. Service firms often look for ways to extend their service mixes by offering new services.

As a new company in the tourism industry, we developed some strategies which directly make our product desired and unique. We mainly pay attention to basic elements in this strategy.

1) We try to partner and cooperate with the firms who are the best and well-known in their industry. Since most customers, especially the young generation, are attracted by brand names we work with famous companies for bringing the best products in the market. For instance Turkish Airlines, Ulusoy ground transportation and Inter-Continental Hotels are some of the companies that are well known and have popular brand name in their industry.

2) A service/product can fulfill its mission of satisfying consumer needs only if it ensures safe and trusted operation. By knowing this fact, we decided to achieve a strategy in which customers receive more benefits while dealing with our services. For instance, a customer can change his/her mind after he/she purchased the product any time he/she wants. Moreover, a customer can postpone his/her travel for the coming season without paying any extra amount of money. Finally, we guaranteed that if any customer wants to change his/her opinion about our offers and services both positively or negatively during the travel route we provide the necessary assistance to make them feel better and to make sure they enjoy their travel. We also provide a quick and efficient service for all customers. For this reason, we will develop a system including online chat services for quick responses to customer's questions and a personalized 15 minute email reply system, a 24 hour phone respond system by professional representatives, and efficient bulletin board system for answering the frequently asked questions. These services would hopefully match the needs of customers as per their preferences in terms of wanting to speak with a live person in real time, searching the website for comparison purposes at their own times, or those who would like written information emailed to them in a timely manner.

On the other hand, we will also develop new products while enhancing current ones every season after the introduction of the old product. We try to do this because we believe that new and attractive things can catch the attention of prospective customers and eventually fill their needs. So, the process that we will be following for developing new products is as follows:

1) Idea generation - to brainstorm on possibilities.

2) Screening process - to filter out ideas that do not match the mission of the organization and to select those that do meet our purpose.

3) Business analysis - to select the best alternatives and assess them to see which ones simultaneously maximize value over time for the organization, employees, customers, and other relevant stakeholders.

4) Development - to perfect the offering where it sells itself.

5) Test marketing - to realize the best ways to enhance the product and sell it. And,

6) Commercialization - making the product fully available to the targeted population.

\section{Pricing Strategy for Services}

Because there is so much competition in the industry, pricing decisions can pose major challenges for service firms in developed nations. In developing a pricing strategy, service marketers must consider the demand for the service, production, marketing, and administrative costs, as well as the influence of competition. Customers may happily pay higher prices for unique or extremely high quality services offered by organizations in a timely manner.

Since we are a new company in the tourism industry, we are trying to complement this disadvantage by offering quality prices with great service. One way to go about doing this is to research the market and get the price 
information of the other firms and then give the lowest price with higher quality. There is a fact that unique and high quality products with low prices and discounts can attract people. Then the challenge becomes to provide an excellent experience for these first customers so they return and so they can effectively market the service through word of mouth advertising.

\section{Distribution Strategy for Services}

A firm's distribution channels play a key role in its marketing strategy because these channels provide the means by which the firm moves the goods and services it produces to ultimate users. Distribution channels perform four important functions.

1) First, they facilitate the exchange process by cutting the number of market place contacts necessary to make a sale.

2) The second function is sorting which alleviates such discrepancies by channeling products to suit both the buyer's and the producer's needs.

3) The third function of marketing channels involves standardizing exchange transactions by setting expectations for products, and it involves the transfer process itself.

4) Finally marketing channels facilitate searches by both buyers and sellers. Buyers search for specific goods and services to fill their needs most effectively, while sellers attempt to learn what buyers want.

We use two types of distribution channels for our product selling strategy. One of the channels is direct selling channel. Direct selling channel provides a way of carrying products directly from a producer to an ultimate user. We can basically make this option available from the e-commerce site on the Internet. Customers can purchase products any time they want from our web site by getting the necessary information about products that they choose at the same time. After the customer finishes his/her purchase we offer an option in which customers can choose the best transportation system and company from our website. In our company list we offer three transportation companies that provide reliable and fast transportation in United States and they are UPS, FedEx and DHL transportation firms. We plan to provide customers a sufficient amount of data about these transportation firms' service units for each state in the United States so that customers can apply the best method for getting their product as soon as possible. The other thing is that these companies are not only the best companies in their industry but also the most reliable firms as well. Trust is one of the important characteristics to develop with customers and difficult to maintain but easy to lose, our main purpose for this case is to deliver our products to our customers in a reliable manner by partner with trusted suppliers.

The other channel we are using for delivering products to customers is the marketing intermediaries. This type has five channels that involve marketing intermediaries.

1) Producer to Wholesaler to Retailer to Customer

2) Producer to Wholesaler to Business User

3) Producer to Agent to Wholesaler to Retailer to Consumer

4) Producer to Agent to Wholesaler to Business User

5) Producer to Agent to Business User

A wholesaler is an intermediary that takes title to the goods and distributes these goods to retailers, other distributors or end consumers. We mainly plan to use "Producer to Agent to Wholesaler to Retail to Consumer" (number 3) and "Producer to Agent to Business User" (number 5) in our sales management. For our program, we are going to collaborate with some of the travel agencies such as CMC Travel Agency in New York, ESTA Travel Agency in Chicago, AIR TOUR in Washington D.C., GEMINI Tourism in Miami. Since these travel agencies have effective connections in their states with both potential customers and potential business users, we are planning to create a good first impression in the tourism industry.

As you see from the locations of the travel agencies we choose to apply this program to customers who are living in New York, Chicago, Washington and Miami. Our main location strategy is to conduct business in the 
states where there is a big tourism potential and purchasing power. That's why we mainly promote our service and product to the high-class states, which are New York, Chicago, Washington D.C., and Miami.

\section{Promotion Strategies}

From the starting day of the business structure to current business structure, promotion plays an important role. Promotion is the best way to provide information to consumers and others, increase the demand of the product, differentiate the product from other firm's product, explain the greater ownership utility of a product to buyers, and stabilize the sales. There are also two kinds of selling methods. One of the methods is personal selling which means the original form of promotion and may be defined as seller's promotional presentation conducted by person-toperson basis with the buyer. The other method is non-personal selling, which means the selling includes advertising, sales promotion, direct marketing, and public relations.

Advertising is any paid, non-personal communication through various media such as radio, television, magazine, etc. We plan to use two different ways which are advertising by sending a small message service to the customer's mobile phones to inform them about our products, and by creating effective and attractive banners for the most visited internet sites such as all the search engines (Yahoo, Google, AltaVista, Iboogie, etc.), chat sites (Geocities, Chatcity, AOL, MSN, etc.), mail services (Hotmail, excite mail, yahoo mail, AOL mail, etc.), university web pages, and similarly used sites in the Internet. In choosing this strategy, we basically find out that young mobile phone and Internet are the most daily used technologies in our lives.

On the other hand, we will also use advertisement on the most popular magazines such as People, Travel, Economy Today, News Week and young generation magazines. Our aim is basically to reach our main audience and provide the service to the targeted population.

\section{Budgeting and Cost Strategies}

Basically there are two cost methods when we try to make a decision on our product costs. Fixed costs: these are costs that must be paid whether or not any revenues are produced. These costs are fixed only over a specified period of time or range of production. And variable costs: these are costs that vary directly with the number of products produced. (Typically includes materials, labor used to produce units, percentage of overhead). In our market plan we basically use the cost-oriented pricing procedures method called the full-cost method. Fullcost pricing uses all relevant variable costs in setting a product's price. In addition, it allocates those fixed costs that cannot be directly attributed to the production of the specific item being priced.

We have two groups of each: two Blue and two Green. In addition to this we have two different packages for these groups. The only differences in their expenses are the flight cost and hotel cost.

\section{Delivering Value by Treating Customers as Guests}

On January $12^{\text {th }} 2004$, Mr. Richard Wagoner, Jr. who is the Chairman \& Chief Executive Officer of General Motors Corporation, lectured at the H. Wayne Huizenga School of Business and Entrepreneurship of Nova Southeastern University at the Distinguished Lecture Series and he presented his suggestions to business leaders about being successful in today's global environment. He said organizations must offer what their customers want or else they will go out of business. For example, in many European countries, people want small cars because gasoline is taxed very heavily which discourages the use of luxury cars for most working professionals. General Motor makes small cars for their customers but a good number of the customers in the United States want large cars instead of small cars for luxury and comfort. Therefore, they are meeting the needs and demands of their customers by producing large cars instead of all small ones. Furthermore, Wagoner said organizations need to consider the global impact of competitive forces on their business even if they are not currently doing business internationally. Globalization is a huge aspect of doing business today and all business professionals and educators must understand its forces in order to effectively meet the current and upcoming challenges. Another important area, according to Richard Wagoner, for practitioners is to consider the diversity of one's employees and customers for success in the 
twenty first century. Wagoner said many firms are still suffering because their customers are becoming more diverse yet their employees are pretty much homogenous and are not able to fully understand the changing needs of their consumer market. As such, organizations must prepare the workforce to:

1. Effectively understand the customers' needs and offer them exactly what they want when they want it while being aware of their changing wants.

2. Understand globalization and be prepared to consistently meet its challenges. And,

3. Diversify the organization's empowered workforce in order to synergistically become competitive while offering all segments of the consumer markets great value.

Understanding the customer and, more importantly, what the customer values, is vital to any business and a diverse workforce is the best way to keep one's finger of the changing pulse of diverse consumers. Part of understanding the customers is not taking anything for granted and not making any assumptions about their needs or wants.

There are many limitations for small businesses due to lack of access to the latest technology and lack of appropriate resources but they can differentiate themselves by consistently treating customers like valued guests. As such, employees need to be educated about hearing their customers effectively, understanding their customers, and exceeding their customers' expectations on a continuous basis by treating them like guests.

\section{Understanding and Effectively Dealing with Challenging Customers}

All customers want their needs filled efficiently and in a timely manner. In other words, they want good service. One objective of this organization is to differentiate itself through quality service. As such, it will educate and empower both internal employees and external constituencies on the value of superior service to all of the guests and how it can be delivered to them on a consistent basis. Good customer service is about providing consistent, high quality attention to the persons who comes to the organization for a service or product. True customer service is about going beyond service by providing a delightful experience for customers every time we interact with them; it is about seeking to understand and providing for each customer's individual requirements; and, furthermore, it is about continually improving our relationship with them and all other stakeholders in the value chain. Many organizations now treat their customers as they would treat their guests. "Guests" are basically customers who enjoy the services and products of an organization. However, there are times when guests do not enjoy their experience due to various reasons and become unhappy.

There is an interesting and popular customer service training video titled "The Guest" which has a simple message: treat your customers like guests at your home. It is true no matter how large or small an organization may be, its success still depends on the quality of service it delivers to its customers. This video uses humor to change the way people see customers and to remind everyone that everything we need to learn about great customer service, we already know. Treating customers as guests is as simple as:
- Welcoming them.
- $\quad$ Using their name.
- $\quad$ Taking care of their needs.
- $\quad$ Thanking them for coming. And
- $\quad$ Inviting them back.

Guest can be challenging and difficult at times. There are many types of unhappy or difficult customers (guests) that one may interact with on a day-to-day basis, regardless of industry or profession. Perhaps, there are many adjectives (or types of guests) that best describe the customers in different industries and the tourism industry is not different. Nonetheless, difficult customers can create much undue stress for employees.

There might be many different reasons for why guests are difficult. Most difficult people are operating from a base of INSECURITY. Like everyone else who has some insecurity, they too, have a need to be understood 
as well as feel welcomed and important. Some difficult guests are often merely expressing a need or frustration; although they may be choosing an inappropriate and impolite way to communicate this need or frustration. One needs to remember that customers are being difficult for their own reasons - not necessarily because of you. The following are some common reasons why customers may be difficult.

1. They are tired or frustrated.

2. They are confused or overwhelmed.

3. They are defending their ego or self-esteem.

4. They have never been in a similar situation before.

5. They feel ignored. Nobody has listened to them.

6. They may be under the influence of alcohol or drugs.

7. They don't speak or understand the language very well.

8. They have been treated poorly in similar circumstances in the past.

9. They are in a bad mood and take it out on you.

10. They are in a hurry or have waited an extended period of time for service.

11. Others.

While many of the challenges may seem demanding at times, "guests" don't really ask for much. They just want to be treated like visitors in your home: they want to feel welcome, be taken care of, get what they came for, be thanked for their visits and invited back. And guests/customers do not necessarily want to be difficult because they simply expect good service. If their challenges and concerns are identified early on and properly handled from the outset, chances are, you can turn things around. The video titled "The Difficult Guest" teaches us that guests can be difficult in three particular ways:

1. Distracted Guests bring all their problems with them. They simply haven't been properly welcomed to your world yet. All they need is to know that they're going to be personally taken care of while they're your guests.

2. Disappointed Guests arrive with expectations that, for one reason or another, end up not being met or fulfilled. They feel let down. Often, the problem is not in what you do or say, but in how you do or say it.

3. Disruptive Guests call for emergency action. They feel ignored or embarrassed, insulted or unfairly treated. You have to deal with them before you can deal with their problem.

Regardless of the challenge, our responsibility is to delightfully provide good service while effectively recognizing, understanding and taking care of difficult guests. Everyone needs to become familiar with common day-to-day strategies needed to make a bad customer situation turn into a smooth and hassle-free process for all those involved. Some of the strategies may include effectively listening to customers, apologizing personally, solving their problems, thanking guests for the opportunity to serve them, and many more with regard to each transaction. Everyone needs to understand these strategies, teach them to others, and continuously improve upon them. In order to handle complaints effectively, one should take the following steps:

1. LISTEN carefully to the complaint to understand both its nature and causes.

2. REPEAT the complaint back to the customer and get acknowledgement that you heard it correctly.

3. APOLOGIZE for the situation, even though it may not be your fault.

4. ACKNOWLEDGE the customer or guest's feelings (anger, frustration, disappointment, etc.).

5. EXPLAIN what action you can and will take to correct the problem for the guest.

6. THANK the guest/customer for bringing the problem to your attention.

7. DOCUMENT the situation and its successful resolution for proactive prevention of such future events so it does not happen again. 
One quick strategy in dealing with difficult guests can be to remember and use the CALM approach.

- $\quad$ Remain Cool. Often difficult customers seem to appear very upset and possibly for some very good reasons that may or may not have much to do with you.

- Apologize for (the mistake or) the situation. It is a good strategy to let the customer know that you are acknowledging his/her concern and frustration about the issue.

- $\quad$ Listen with empathy. This is where you find out the real reasons why the customer is upset or concerned. Do not make assumptions. If appropriate, you can use empathic listening skills to confirm your understanding of his/her concerns.

- $\quad$ Make it right by taking care of his/her needs immediately. Take care of the customers concerns or personally contact the right person who can take care of the customer immediately.

\section{Summary}

Research shows that there is great potential for the younger generation (Generation Y) in America to use diverse services in the tourism industry. It is for this reason that the company will initially focus mainly on university students and recent graduates that tend to be part of the Generation Y group. One of the important elements of the tourism industry is introducing and serving various cultural aspects of different people. We also found that consumers look for better services even if it means paying more money. We believe that creating an effective marketing plan is essential in offering the best possible product to the targeted population. This must be supplemented with superior service to all guests in order to differentiate the organization from competitors.

To be effective, the organization must monitor all current and prospective competitor's marketing activities, their products, distribution channels, prices, and promotional efforts. The U.S. market for the young generation seems to be very attractive to these Turkish entrepreneurs because of the highly competitive market already present and the high potential for attracting the younger generation to diverse services.

While geographic factors such as gender, age group and culture can be used to generate potential clients, the cost must match their ability to purchase our services. Since the company is new, it might not be very successful in generating high income initially if it operates by itself. To effectively complement this lack of having a customer base, we plan on co-operating with leading companies in the industry like Turkish airlines and the Inter Continental group of hotels. The customer service department must be able to offer excellent services so as to attract more guests. Distribution channels would also play a key role in the creation of the company and the channels used will be direct selling and using intermediaries like agents to sell our products. Promotion strategies employed can include offering a free ticket for every twenty tickets purchased, offer discounts to repeat clients, and advertising through email, text messages, university websites, and online search engines catering to Generation Y age group. Finally, strategies associated with delivering superior service by treating customers like guests is offered to the targeted population in order to differentiate the firm's services from competitors and to secure repeat guests and more business through the "word-of-mouth" advertisement.

\section{Bibliography}

1. Desouza, K, and Awazu, Y. (2003). “Knowledge Management.” HR Magazine. November, pages 107-112.

2. Donnelly, Ally (2003). “Air Support.” Time Magazine. December 1 $1^{\text {st }}$. Pages 62-63.

3. Eisner, Susan (2004). Teaching Generation Y: Three Initiatives. Presented at the Teaching and Learning Conference (TLC). Orlando, Florida. January 5-9.

4. Gable, W., and Ellig, J. (1993). Introduction to Market-Based Management. Fairfax, VA: Center for Market Processes.

5. Hackney, Skil (2003). "Streamlining HR Processes to Improve ROI." Financial Executive. November 2003, pg. 40-42.

6. Jones, Gareth R., George, Jennifer M. (2003). Contemporary Management. Third ed. ISBN: 007291890x. Textbook Website: http://www.mhhe.com/jones3e. 
7. Mujtaba, Bahaudin (2004). Empowering the Workforce to Deliver Superior Value through the Development of a Customer Oriented Culture in Developing Countries. Proceedings of the Fourth Annual International Business Research Conference. University of North Florida. (February 2004). Jacksonville, FL.

8. Mujtaba, B. (2003). Ingredients for Empowering the Afghan Workforce to Deliver Superior Value. Presented at the Society for Afghan Engineers (SAE). Conference titled "International Planning Conference for the Empowerment of Afghan Professionals." Hoboken, New Jersey. October 3-6, 2003. SAE Website: http://afghan-engineers.org.

9. Pohlman, Randolph A. \& Gardiner, Gareth S. (2000). Value-Driven Management: How to Create and Maximize Value Over Time for Organizational Success. ISBN: 0-8144-0485-5.

10. The Guest, (2004). Follow up videos is titled The Difficult Guest. Phone: (800) 575-4001 or (561) 5754001. Retrieved on 9/5/03 from: http://www.customerserviceuniversity.com/theguest.html

11. Weinstein, Art \& Johnson, Bill (2004). Superior Customer Value in New Economy. Second Edition. CRC Press.

\section{Notes}

